\title{
Study on the Constructivist Utopia of Vsevolod Meyerhold
}

\author{
Vadim Shcherbakov \\ Department for Research and Publication of Meyerhold's Legacy \\ The State Institute for Art Studies \\ Moscow, Russia \\ E-mail: vadshcher@gmail.com
}

\begin{abstract}
Meyerhold was always fascinated by the concepts of art changing and creating life. He was deeply concerned by the Russians' headfast unwillingness to obey the slow course of evolution. The director's experiments in establishing the performance as a mass meeting and his concept of monumental revolutionary propaganda, as they had been manifested in The RSFSR-1 Theatre, proved to be successful and convincing. Nevertheless, the Moscow Soviet closed the theater. As Meyerhold trusted the party leaders he considered closing his theater a proof of the fact that the Soviet country was in no need of professional stage art. Thereby the constructivist idea of art which aims to design life in accordance with artistic laws shows the way out of the impasse. If the theater artist must be effectively involved in the process of creating a new harmonious human being, Meyerhold will develop the methods of actors' training to bring him up. The method was found in Biomechanics.
\end{abstract}

Keywords-Vsevolod Meyerhold; constructivism; Biomechanics; New Man producing; Utopia; art creating life; mass spectacles; Proletarian Culture

\section{INTRODUCTION}

The Constructivists were attracted to the language of numbers and mathematical symbols. Its pure clarity seemed adequate to the tasks set for the art by the artists striving to organize life. It was therefore only logical that one of their conceptual exhibitions was entitled "5 x $5=25 "$. The exposition of five artists who submitted five works each reflecting the meaning of the equation - caught the attention of Vsevolod Meyerhold. Of course, he was already familiar with the ideas of the Constructivists and with their artistic work. In the early 1920s the Reformer of Theatre becomes an integral part of the Constructivist group. His first - and the most important - response to the Constructivists ${ }^{6}$ slogans was Biomechanics. To collate the aforesaid facts - or, speaking the algebraic language, variables — one would need to find the exact formula of constructivism in the theatre and to determine the place of Meyerhold's Biomechanics in that formula.

Constructivism in theatre is commonly understood as experiments of collaboration of theatre directors and artists engaged, in one way or other, in this art movement. Some of these experiments opened new horizons in theatre development and made an impact on acting. But more often they represented examples of successful utilization of fashionable design. No matter how strongly the Constructivists struggled against the dogma of aesthetic perception of an artwork as a value in itself, their creations had obvious stylistic features that were able to exist independently of their ideological concepts. The constructivist art forms developed a fashion trend that lasted for a while, and theatre did not hesitate to make use of it.

Alexandre Tairov at the Kamerny Theatre did over a dozen productions in association with artists who belonged to the group of Constructivists. He knew how to exploit the fashion and how to adapt novel discoveries in the visual arts to the needs of theatre. Tairov was not interested in the task of life construction, which was the key idea of the Constructivists. Throughout his artistic life Tairov viewed theatre as a professional art, a festival of actors' skills, which create emotionally rich images.

In contrast to Tairov, Meyerhold got carried away by the new ideas. He opened himself to these ideas and developed his own artistic response to their challenges. He sincerely believed that the theatre is only a tool for transforming life. But even with this belief Meyerhold appeared to be able to find in each case the most theatrical decisions. No wonder he was unofficially assigned the title of Master". He knew his instrument very well and felt it thoroughly.

\section{MEYERHOLD`s CONSTRUCTIVIST PRODUCTIONS}

Meyerhold staged only three productions in the constructivist style — "The Magnanimous Cuckold", "The Death of Tarelkin" (both in 1922) and "The Earth Rampant" (1923). Already in the first production Meyerhold exhaustively and clearly demonstrated principles of the new scenography. The set design for "Cuckold" created by Lubov" Popova became a helpful "instrument for actors". The construction did not suggest any image, decisively breaking with illusionism. What it presented was an artistically organized combination of installation sites on various levels, walkways, stairs, ramps and rotating elements. Of course, at times the audience ascribed certain images to the wooden framework. Some, following the plot of Fernand Krommelink's farce thought they recognized the mill. For Sergei Tretyakov it was "the scaffold of the world under 
construction" [1] - a symbol of contemporaneity of the new theatrical art and its consonance with "the present moment".

This was clearly contrary to the pronouncements of the creators of the production, and later even forced the art historians to resort to all sorts of apologetic arguments - like such "visuality" smuggled itself into the performance against the set designer's and director's will as a consequence of their generic artistic thinking, etc. In reality, it was not a result of the authors' subconsciousness but should rather be explained by the fundamental property of the acting. In Tadeusz Kantor's analysis of Constructivism we find a precisely formulated "superobjective" of Constructivism: an artist sought to create a material partner for actors, to have an additional performer capable of his own actions on stage [2]. And as we know, any action that happens on stage - no matter how formal, technical or "non-object" it is - would inevitably be interpreted by the audience as representing a certain image. Something very similar can, of course, be said about perception of other art forms: listening to music, looking at an ornament or at an abstract painting, we often look for and do find a story. However, the combination of concrete physical actions performed by a human being on stage and the artificially organized acting space allows and even dictates to search for figurative meanings.

The idea of giving up individual characters' costumes was another principle that also worked remarkably well in The Magnanimous Cuckold". The actors were dressed in the unified production clothes made of gray-blue canvas, the only difference being that female characters were dressed in skirts instead of pants. This unprecedented combination of flare and breeches, performing the function of working overalls worn by all self-respecting artisans, evoked pleasant futuristic thoughts about the wonderful future of the Soviet industry. The uniformity of the costumes was the best way to emphasize the collectivist pathos of the performance. Watching the group of muscular young people so efficiently and harmoniously working as one body, the audience inevitably got to believe in the imminent coming of the new world.

Thus, Meyerhold's constructivist creations embodied many of the maxims declared by the ideologues of the movement. It has to be added that in all the three productions the director determinately breaks with the proscenium stage. These productions did not need any specially equipped theatre space. The scenery construction could easily be set up anywhere - be it a town square in the open air. Theatre art explicitly declared its intention to go out in the city, to become part of it, to organize it in a new way by providing expressive means to embody human emotions.

Probably the only requirement of the constructivist dogma that the three Meyerhold productions could not meet in full was the principle of giving up professional acting. Watching the well-trained actors following the director's instructions, one could hardly believe that Soviet proletarians would be able to reach this level of acting any time soon. However, the young age of the performers left the theoreticians some hope. Among the cast, only the names of Igor Ilinsky and Maria Babanova were already familiar to the
Moscow public. The others were completely unknown undergraduate students of The State Higher Theatre Workshops (GVYTM). Yet, being in the second year of studies, the young actors already possessed the skills that could impress the spoiled Moscow audience. So for promoters of the Productivist Art" this was evidence of a great potential of Meyerhold's Biomechanics as a teaching method.

As far as painting was concerned, the constructivist ideology worked very well. The notion of an intrinsic aesthetic value of a painting was already a thing of the past. An artist was no longer supposed to portray anything. He gives away the easel and takes up a machine in order to organize a new mode of life in its various practical forms to the best of his taste and ability. Being very critical of the easel art, the constructivists did not deny the need for a professional artist. They rejected only the word that was compromised by having served the power and the moneybags for centuries. At the same time, they emphasized the important role of a creator of artistic forms.

\section{PRODUCTIVISM THEORY ON THEATRE}

It was not so easy with the constructivist concept of theatre. The traditional situation where a handful of professionals perform in front of a crowd of spectators who simply sit in a dark auditorium, was declared outdated and even class-alien. The future belonged to the free play of laborers"!

A keen interest in the scientific approach to the superstructure" problems, made the constructivists to take up the theory of conditional and association reflexes, gleaned from the works of Ivan Pavlov and Vladimir Bekhterev. Life of individuals and groups is characterized by periodic accumulation of mental tension followed by an emotional discharge [3]. A proletarian experiences, say, anger against the intrigues of the world imperialism. Or, on the contrary, he is rejoicing over the fact that he lives in the world's only country where the ultimately true ideology has prevailed. These feelings gradually grow stronger, until it comes to a spontaneous emission in a performance in which the proletarian comes out against or glorifies the relevant source of emotional tension.

It's curious that most often the emotion of exultation is mentioned in such theoretical constructs. In the early 1920s they had not gone as far as open adoration before the country leaders. But the maxim of the best society in the world was already firmly implanted in people's minds. It was for that reason that the Soviet worker could do nothing but rejoice in his spare time.

Thus, mass performances engaging people of labour were supposed to replace professional theatre. Admitting that an artist is a specialist in producing intellectual values in the area of emotions, the ideologists of the new culture easily found a place for a stage director. A stage director was defined as an organizer of mass spectacles. Alexei Gan the author of the Constructivism Manifesto" - called himself a designer of mass action". Boris Arvatov, an active ideologist of Proletarian Culture who was close to the 
Constructivists, stated that -..a stage director should be turned into a master of ceremonies of labor and life" [4]. But then, how would one define the performer, the participant of a spectacle?

This brings us to the most interesting point. The Productivism" model of the future theatre was strongly focused on proletarian amateur acting. To become real" i.e. life-organizing rather than life-reflecting, the constructivist theatre was supposed to - - . transform an actor from a specialist in aesthetic action into a harmonious socially active human being" [5]. It is important to note that the aesthetical here is replaced with the social, recognizing as artistically valuable only that what was socially significant.

But the most essential message in the quoted passage is the confidence in the emergence of a new man who will be capable of embodying his emotions in compelling and spectacular performances. Of course, such a harmonious individual had yet to be created. Alexei Gastev, the constructivist poet and Director of the Central Institute of Labor wrote in one of his poems:

tet us build ourselves!

The humankind has learned to cultivate things.

The time has come for a careful cultivation of a man" [6].

The task of a -areful cultivation" generated a great number of new trends in the circle of radical artists. Some of them got interested in theatricalization of physical culture. Others got carried away with the idea of introducing artistic elements in the universal military training [7] or integrating Faylorism" in the organization of labor. Biomechanics seemed to be able to unite all, as it combined all of those tasks. Biomechanics was based on a well-developed muscular system and reactions. It suggested exercises that helped to bring to perfection the attack movements. Meyerhold insisted that biomechanics employed, among other things, Frederick Taylor's principles, helping an actor to economically expend the energy when fulfilling the director's instructions. No wonder Arvatov, in an article written in 1922, praised to the skies the new phenomenon of the constructivist theatre: Being built on a rational spending of motion and on psychophysical laws of the human body, Biomechanics, for the first time in the world history, tries to teach what must be learnt by anyone who wants to be a efficient member of the society. Biomechanics has finally managed to bring together organization in art and in life" [8].

Meyerhold also made loud statements in favor of the Productivism" theory. In 1922 his relationship with Constructivism was very harmonious. One can say that Meyerhold was always infatuated with the life-constructing concept of the art. Clearly, he shared the strong reluctance to accept the slow pace of life evolution that was typical of a Russian man. Characterized by Mikhail Chekhov as A schoolboy pretending to be a Bolshevik" [9], he was passionately involved in doing away with the inert matter both in the days of the Russian Symbolism and in the time of The Theatre October".
The experience of a performance-rally and of monumental revolutionary propaganda with the means of performing art presented by Meyerhold with The RSFSR-1 Theatre, seemed successful and convincing. But the state authorities closed the Theatre, and Meyerhold was deprived of the stage and no longer had the opportunity to serve the power with his extraordinary spectacles" [10]. Just to think of the fact that it was not the Tsarism and not the capitalist moneybag who took away his theatre, but the very same Bolshevik government that the Director welcomed so much totally sharing their ideals.

Meyerhold trusted the Party leaders, and he apparently accepted the closure of his theatre as an evidence that the Soviet country did not need the new professional performing art. It seemed to indicate that the Bolsheviks wanted to keep the traditional museum-like theatres as they were, but intended to develop other forms of acting as part of the future proletarian culture. The way out was suggested by the constructivist ideas of life-constructing art. Once an artist was expected to get engaged in the process of creating a new harmonious man, Meyerhold would invent a new system of training such a man by the theatre.

The Theatre Bulletin" (VestnikTeatra) in the issue dated February 22, 1921 announced opening of a Theatre Technical School under Meyerhold's leadership. The industrial accent was manifested even in the fact that the new institution was called Fechnical School" rather than Studio" or Academy". The curriculum would include, among other subjects, faboratory research and demonstration of work on specific material that reveals the industrial nature of theatre art". The new School aimed to facilitate the formation of -self-motivated associations of students who will be commissioned to create performances that would bring them to direct participation in the public industrial life". At the last stage of training the apprentices were supposed to take up the following disciplines: -ereation of artistic design for industrial processes in relation to the organizational science; mastering the method of simplified performances and folk festivals" [11].

By the time the School opened in September 1921 it had already been renamed into Workshops". At first it was called GVYRM (State Higher Director's Workshop) and later, when an acting class was opened, the School got the title of Theatre Worskops (GVYTM). This did not mean that Meyerhold had given away the technological approach to actors' education. But it was important for him to demonstrate a proximity to Higher Art and Technical Workshops (VHUTEMAS) and the Constructivists.

Being busy with organization of the Workshops, Meyerhold is at the same time actively involved in yet another significant event. He makes a presentation at a meeting of the Supreme Council for Physical Culture reporting on his efforts and achievements in the area of integrating elements of theatre in mass sports. A newspaper report says -Meyerhold wants to deal with the problems of today's theatre and the decline of theatrical culture". His aim is to liberate the dramatic action of the stifling atmosphere of the wings andthe picture frame stage" and to identify a 
new mass theatre culture that would be appealing to the new man". Meyerhold partly connects the problem of modern theatre with the changes in the economic policy, which brought about a farce and operetta boom. He believes that indoor theatre model is outdated and that a revival of theatrical culture is only possible -on the territory of the Universal Military Training and not on the premises of professional theatre" [12].

In the Workshops and in his activities under the Supreme Council for Physical Culture (headed by Nikolai Podvoiskiy, the initiator of military training of Russian citizens) Meyerhold's main teaching method was Biomechanics. Considering theatre making as a process of creating plastic forms in space", Meyerhold developed a set of exercises. The exercises represented miniature plays with simple plots, and consisted of expressive movements of a human body that alternated in a complex rhythm. Meyerhold's exercises differed fundamentally from traditional stage movement training, the main difference being that they did not set any acting task. A performer was not supposed to play.

While the exercises were meant to be demonstrated in front of a potential audience, theyrequired from a performer only perfect execution in terms of forms and rhythm. On the viewers, nevertheless, exercises produced an impression of perfectly mastered acting!

Again, it is the law of a theatrical action at work - a properly structured and dynamically executed sequence of movements inevitably creates a flow of images in the minds of the spectators. The audience completes the images, fills them up with meanings, and derives a tune out of the cleverly constructed sequence of movements.

Meyerhold's method apparently seemed a priceless instrument to fulfill the tasks of constructivists in upbringing theatrically literate people en mass. It manifested that there was no need to develop professional acting skills and abilities in order to be a performer. All that was needed to stage a mass performance was to provide the laborers with a set of well-designed forms in space".

The gesture vocabulary and story lines for his exercises Meyerhold took from his previous practical experience. Exploring the nature and the expressive possibilities of grotesque in his Petersburg studio, he worked on refining pantomimes that included shooting the bow, playing forse and rider", stabbing with a dagger and striking with a foot. In addition to refining the forms in space, the result achieved by Meyerhold through his work at the Studio was defining grotesque as a montage of incompatible extremes.

This kind of montage moves the dramatic conflict which is the essence of dramatic action - inside an artistic image. Even before any collision with other masks takes place, a grotesque character carries a conflict, and is therefore already interesting to the audience. Such a montage reveals unusual connections between juxtaposed extremes and serves to sharpen the paradox that underlies an artistic image. Moreover, grotesque as such is an embodiment of a logical paradox, its visible and sensuously perceived incarnation.
Eugenio Barba in his Đictionary of Theatre Anthropology", reflecting on Biomechanics, suggests that it is a new name for what used to be called grotesque [13]. I would rather consider it to be a further and higher stage of development of Meyerhold's grotesque. Already in the prerevolutionary performances, this intricate manner could at times be seen as the director's special style that would enable him to express his -montage-like" vision of life. In the 1920s it turns into the method of paradoxical theatre.

In the movement exercises Meyerhold uses the same principle of montage that he used in grotesque pantomimes when working at the Studio. He gets rid only of the signs of grotesque. Similar to the pantomime, the conflict is transferred into the actor's body. But in this case it is not properties of the character that are conflicting with each other but the differently directed movements - the right arm fights with the left foot, the elbow struggles with the ear, the forehead joins battle with a finger, etc. And all of them together fight with the laws of gravity.

Biomechanics is an extract of theatricality, it represents the result of Meyerhold studies of the laws of expressive movement. Each form in space is a hieroglyphics with its own set of meanings. Biomechanics selects the most conflicting, play-provoking and therefore the most effective hieroglyphics.

However, the constructivist context of this presentation makes me set aside the specifically theatrical discoveries of Biomechanics. These discoveries will work in Meyerhold's performances, will help develop the unique skills of his actors and, with the help of his students, be introduced into film-making. In the frame of this essay it is worth to go back to the life-constructing ideas that Meyerhold was obsessed with in 1922.

Constructivist poet and Rector of the Workshops, Ivan Aksyonov wrote about the future of mass performing art: What will a performer-proletarian use when acting? The answer is evident but needs to be specified. He will use the industrial production instruments. This is the only thing that we can say for sure. The rest is subject to speculations. In any case, a simple pantomime where people are waving tongs and chisel before a milling machine is not enough. Performance-making requires the elements that make an impact on the feelings of the audience by affecting the collective attention. The voltage of the attention is maintained by the rhythmic diversity of these elements" [14].

I am not going to discuss here the ridiculous idea that the choice of production instruments for a performance depends on the class to which the performers belong. Moreover, Aksyonov jokingly degrades production instruments to the tools of labor. It seems that Aksyonov needs the imaginary industrial pantomime that results from such a degrading only to indicate that the objective of acting is to process human feelings. I wonder if it would be just as much fun for him to watch a rough file thoroughly processing an intermediate product of love which is turned by a proletarian-performer into a polished gear capable to work without interruption in everyday life. 
In any case, as far as we know, biomechanical experiments with imaginary antediluvian weapons of murder (stone, bow, dagger) did not tempt Aksyonov to make jokes. Probably it can be explained by the fact that these forms were characterized by refined conditionality. The subjects of biomechanical exercises seemed outdated to the contemporaries even at that time. However, it is a combination of concrete movements with their hieroglyphic ability to absorb complex meanings, which made Biomechanics so fascinating for the Muscovites in 1922.

The Biomechanics rhetoric and the theoretical statements made by Meyerhold and his students sounded impressive as well: the human body is the machine, and the brain is the driver. Exercises help a student to rationally organize his corporal instrument and provide him with a comprehensive set of forms for acting out any theatre play. The extreme expressiveness of biomechanical movements allows an actor to maximize the artistic impact and minimize the spending of psychophysical energy. This training method brings up the Taylor-Gastev type of a speedy man" capable of seriously improving productivity of his labor in any field.

In the midst of the war and revolution ravages, and total deficit of all vital things, these speeches sounded cheerful and presented new horizons for development. The engineering vocabulary seemed to be bringing closer the upcoming era of industrialization and opened the doors to the wonderful kingdom of joyful labor.

But actually the theatrical aspect of Biomechanics seems to be a subordinate factor for Meyerhold at that time. For him the theatrical art that he had studied so thoroughly is primarily a conductor or an assistant on the way to a new organization of life. His theatre productions seem to be no more than intermediary results of previous theatre experiments or sketches of future theatrical shows that can be put up in any space, including factory premises, construction sites, parks, stadiums or urban environment.

His main objective is now to promote the biomechanical method of upbringing new perfect people. This message can be clearly heard in Meyerhold's writings of that time.

After the premiere of -Magnanimous Cuckold" on April 25, 1922 it was decided to merge The Actor's Theatre (TeatrAktiora) - where the production was staged - and the Meyerhold's Workshops. The draft announcement, apparently prepared for the press, states that the forms of acting demonstrated by associates of The Actor's Theatre are free manifestation of their inborn talent and training that characterizes them as people of the present time" [15].

On June 12, 1922 Meyerhold made a famous speech at the Small Hall of the Conservatory on Actor of the Future and Biomechanics". It was then published in the Hermitage" magazine, and that is what it said:

Work should become easy, pleasant and continuous, and the art should be treated not so much as an entertainment but rather be utilized by the new class as something vitally necessary, that facilitates the labor processes; we will have to change the forms of our creative work, as well as the method. [...] An actor's work in the labor society will be considered a product required for proper organization of work of all citizens. But in labor processes it is important not only to manage your leisure time but also to find such movements in the flow of work that would ensure a maximum use of working time. We can see that movements of a skilled worker are characterized by: 1) lack of unnecessary unproductive movements, 2) rhythm, 3) ability to find the centre of gravity for the body, and 4) steadiness. Such movements are dance-like'. An experienced worker reminds of a dancer and his work process is on the verge of being an art; watching someone who works in a proper way brings a kind of pleasure. [...]

Constructivism required that an artist should be at the same time an engineer. Art should be based on scientific grounds, and an artist's work must be conscious. Acting is mostly the skill of organizing the actor's material i.e. an actor should be able to properly use the expressive means of his body" [16].

The correspondent of Theatre in Moscow" adds to the publication in the Hermitage" yet another and very important quotation from Meyerhold's presentation: An actor will take up a function of a worker, and in the leisure time will perform in front of his colleagues. In this way we will achieve a wonderful continuity of labour..." [17]

That is, according to Meyerhold, acting as an independent profession is only a temporary thing. With all the benefits that existence of professional actors may bring, their professional activity should be limited to a certain period of transition. Ideally, according to constructivists, the future must belong to amateur performing art that would involve proletarian masses.

The Workshops student Zinaida Reich had more to say about this:"A mass performance turns from a dreamlike flying carpet into actual reality. The magic carpet" transformed through people's labor from a fantastic image into a wonderful real airplane is no longer a miracle from a fairy tale. In the same way, with the help of Biomechanics, there will be no need to dream of a mass performance or theorize on it or experiment with little success. We know that in five or six years from now there will be such theatrical festivals that will help us grasp the joy of being. The labor processes, illumined with knowledge of the biomechanical laws, will be transformed into the healthy work-art or workjoy. And that is what proletarians of the world strive at" [18].

In September 1922 Meyerhold was taking his vacation in Yalta. Local theatre makers invited him to give a lecture on contemporary performing art. In the draft notes that are at our disposal today we see that Meyerhold almost never mentions Moscow theatres in his lecture. Moscow theatres are only present as a list of what he does not want to see in modern theatre art as they are either dead or dying. For Meyerhold they are no more than a wasteland of negative examples. The positive programme is made up of unexpected references that are very far from theatre practice. I cannot deny myself the pleasure of giving a few abridged quotations from the notes: 
[...] Improving the flying abilities of birds. The slowness of human nature improvement. [...]

First flying insects that emerged in ancient geological epoch (that begins in the Paleozoic era in the Devonian period).

At the end of the following Carboniferous period the first heavy, awkward, toothy pterodactyl took off heavily into the air. One hundred and fifty million years have elapsed since then. The nature continues to improve this monster through an endless series of successive experiments.

In the following Mesozoic era in the end of the Triassic period improved forms of life emerge that are more similar to modern ones. For instance, the famous Archaeopteryx imprint kept in Berlin is a demonstration of the degree to which nature had perfected the prehistoric monstrous pterodactyl.

[...] The number of the cars available and produced in the United States annually: in 1900 13524 available and about 5000 produced; in $1918 \sim 444349$ available and 178557 produced; in $1920 \sim 9,118,000$ available and 2,200,000 produced. Now there are 10 million cars and 2.5 million produced.

Such a thriving industry has been created in the last 25 years. (It is particularly true of the metallurgy - iron and steel industry — and in the construction industry).

If we compare the archaeopteryx (the Mesozoic era flying monster) of a later period with the heavy, awkward, toothy pterodactyl of the Carboniferous period in the early Mesozoic era, we can see that it took the nature about 150 million years, an endless series of successive experiments and tireless work to upgrade the epiterranean flying animal. (What an evolution from the flying insects of Paleozoic era to the archaeopteryx of the Mesozoic era!)" [19].

The enigmatic logic of the speaker is not too difficult to discern if we remember Meyerhold's commitment to the constructivist approach to the tasks of the art. References to paleozoology evidently were meant to show the snail's pace of the general evolution. For hundreds of millions years the prehistoric" flesh has been producing a living mechanism for the flight. Then the nature slowly, through a legion of generations, transformed the clumsy pterodactyl into a primal bird whose aeronautic machine was already comparable in complexity and efficiency with modern engines.

The American society built on the principles of freedom is industrializing at an unprecedented pace that is not seen anywhere in Europe. They are creating a mechanized civilization, capable of producing a huge number of machines, which make easier the manual labor.

The October Revolution created a country of new freedom, the only state in the world that develops according to a scientific plan. The Soviet society will be able to speed up the processes that the nature was so slow at. By spurring the -decrepit horse of history", it will establish a mass production of the new man.
This man will be a finely tuned machine that will inevitably be able to outdo the American capitalists. They defeat us in terms of machines, and we will beat them in terms of people!

Many other statements made by Meyerhold at that time confirm that those were the messages of the lecture in Yalta. I will give the most vivid examples. After his return to Moscow, Meyerhold was speaking at the opening of The Theatre Institute, formed by the merger of several independent workshops. In his speech he explained in very clear terms the aim of his constructivist training: The Institute (GITIS) is a theatre school of the new type and is meant to create a new type of actor, who will be a new human being. Instead of the methods based on emotions and psychology that may bring to the psychological anguish due to lack of knowledge of the human body structure, we will train the actor with the help of exact sciences, developing his intellect, as well as with the help of sports and biomechanical exercises. The Institute will create a matrix of organized man who will be able to serve the mission of what is called Theatre and that is to organize the masses: a social demonstration of perfectly organized human entities" [20].

According to Meyerhold, Biomechanics teaches the ability to turn chaos into well-ordered cosmos. With the help of Biomechanics the new man will be able to control his body, which inevitably will give him power over his emotions, feelings and psyche. It allows to organize all types of the matter, and hence to rationalize them, to cleanse it from dark passions and ugliness. As long as this method is taught only in the theatre school, the actor trained in this way will represent an example of a harmonious personality. But the victorious march of the constructivist approach to reality will unavoidably lead to the mass production of the new man. These are the true goals of the art, and that is what Meyerhold expects from implementation of Biomechanics into life!

The constructivists and Meyerhold traveled the same distance in their motion towards each other. Thus, the formula of the relationship between the Theatre Constructivism (TC) and Meyerhold's Biomechanics (MB) can be represented as an accurate identity:

$\mathrm{TC}=\mathrm{MB}$.

Which was to be determined.

\section{CONCLUSION}

The turning point in Meyerhold's perception of the ultimate goals of the art happens in 1924, when a new theatre with a clownish name TIM [21] appeared on Moscow theatre map. The new theatre opened with the farcical, lyrical and pathetic production of The Forest". Pavel Markov comments that this production is a manifestation of a new unexpected phenomenon that may be defined as Shakespearean Theatre of contemporary Russia" [22]. The production staged at the highest professional level was extremely popular with the public and kept in the repertory for a long time - until the day the TIM was closed it was performed 1300 times. The enormous success of The 
Forest" made Meyerhold forget the constructivist approach to the art for good.

Since then Biomechanics for Meyerhold remains a training method, a set of exercises and the means of constructing a character through paradox. He also keeps his artistic relations with constructivists - from Alexander Rodchenko to Igor Sel'vinskiy. The clearly discernible hallmarks of the style and forms created by discoveries of constructivists did not go away either. These signs can be seen in what is left from the time of the Meyerhold Theatre - posters, stage designs and layouts of printed materials.

\section{REFERENCES}

[1] Sergei Tretyakov. The Magnanimous Cuckold" // Zrelishcha, 1922, Vol. 8, p. 12.

[2] Ref. Zbignev Osinskiy.Traditions of Meyerhold in Poland (after 1945): Jerzy Grotowski, Jerzy Yarotsky, Tadeusz Kantor // Problems of the Theatre. Proscaenium, 2012, Vol. 3-4, pp. 288-289.

[3] With onset of the communist labour a new production environment is created which will bring about new systems of emotional discharge, both for a collective and for an individual human being", - wrote Alexei Gan in The Fight for a Mass Performance // On Theatre. A collection of articles. Tver', 1922, p. 73.

[4] Boris Arvatov. Theatre as Production. // On Theatre, p. 115

[5] Ibid.

[6] Cit. in: Elena Sidorina, Russian Constructivism: Sources, Ideas, Practice. Moscow, 1995, p. 79.

[7] VSEVOBUCH (The Universal Military Training) — was urged by the 7th Congress of Bolshevik Party in 1918, a system of compulsory military training for men, which was govern by the People's Commissariat of Military Affairs.

[8] Boris Arvatov. Theatre as Production // On Theatre, p. 120.

[9] Mikhail Chekhov. Creative Legacy. Moscow, Iskusstvo, 1995, Vol. 2, p. 364.

[10] These words were used as subtitle of Mayakovski's The Mystery Buff" staged by Meyerhold in 1921 in The RSFSR-1 Theatre.

[11] Theatre Technical School // VestnikTeatra, 1921, February 22, Vol. 83-84.

[12] Tefizkult // Ekran, 1921, December 16-18, Vol. 15, p. 7.

[13] Eugenio Barba, Nicola Savareze. Dictionary of Theatre Anthropology. Moscow, ART", 2010, pp. 52-54.

[14] Ivan Aksionov. Theatre on the Move // On Theatre, pp. 84-85.

[15] Ref. Announcement of the Merge of the Actor's Theatre and Meyerhold's Free Workshop. RGALI, 963, 1, 16, p.3.

[16] VasiliyFiodorov. An Actor of the Future. VsevolodMeyerhold's Talk at the Small Hall of the Conservatory // Hermitage, June 20-26, Vol. 6, pp. 10-11.

[17] An Actor of the Future and Biomechanics // Tearal'nayaMoskva, 1922, Vol. 45, June 20-25, p. 10.

[18] Rich [Zinaida Reich], There Are Eighty of Us // Hermitage, 1922, June 27-30, July 1-3, Vol. 7.

[19] RGALI, 998, 1, 493, pp. 4-10.

[20] Bio-mechanics. Excerpts from Conversations with Students of Meyerhold's Workshops // Zrelishcha, 1922, October 31- November 5, Vol. 10.

[21] Abbreviation of The Theatre named after Meyerhold.

[22] Pavel Markov. On Theatre. Moscow, Iskusstvo, 1976, Vol. 3, p. 143. 